\title{
IMPLEMENTASI JARINGAN SYARAF TIRUAN BACKPROPAGATION UNTUK MENGIDENTIFIKASI JENIS TANAMAN MENGKUDU BERDASARKAN TEKSTUR BUAH
}

\author{
Muhammad Jurnalies Habbibie \\ ${ }^{1}$ Program Studi Teknik Informatika, Fakultas Industri Kreatif dan Telematika, Universitas Trilogi \\ email: habibie598@gmail.com
}

\begin{abstract}
Noni plants are plants that are widely used for herbal medicine. Noni plants have various types. Noni has a type of fruit that is poisonous to distinguish is difficult because noni fruit has a similar texture in terms of fruit. Identification of the type of noni fruit using backpropagation artificial neural network based on fruit texture to identify the type of noni in order to distinguish which nontoxic and poisonous fruit types. Characteristics used include in terms of homogeneity, energy, entropy, and contrast. The results of the testing process obtained a numerical value of $86 \%$ accuracy on the results of the $10 \mathrm{~cm}$ MSE 1 - 10 distance ANN test.
\end{abstract}

Keywords: Noni plants, image processing, artificial neural networks, backpropagation.

\section{PENDAHUluAN}

Teknologi dalam penerapan ilmu biologi mengalami kenaikan yang sangat tajam baik dari segi bidang industri, kehutanan, maupun pertanian. Setiap orang untuk mencari suatu produk yang berkualitas akan selalu membutuhkan identifikasi data yang terpercaya untuk setiap jenis spesies maupun marga atau yang lain. Menentukan jenis tanaman mengkudu merupakan pemanfaatan yang bisa dilakukan dengan menerapkan kecerdasan buatan untuk mengidentifikasi jenis mengkudu. Mengkudu merupakan tanaman yang banyak manfaatnya untuk dijadikan produk obat maupun yang lain.

Identifikasi pada suatu tanaman bisa dilihat dari data yang digunakan berupa dari segi buah, daun, batang, dan lainnya. Penelitian ini memfokuskan menggunakan buah tanaman mengkudu yang akan dijadikan objek dari proses identifikasi. Hal tersebut menjadi faktor yang signifikan untuk dilakukan pengamatan berfokus pada citra.

Tanaman mengkudu yang biasa dikenal juga dengan nama pace (Morinda Citrifolia L.) merupakan tanaman yang digunakan untuk pengobatan herbal. Jenis Tanaman mengkudu terdiri dari mengkudu maluku, mengkudu bogor, dan lain-lain. Setiap tanaman mengkudu mempunyai berbagai ciri yang berbeda dari segi fisik buah seperti panjang, bentuk, maupun warna. Mengkudu mempunyai kurang lebih 80 jenis spesies, dari 80 jenis hanya 20 jenis yang dapat dikonsumsi namun sisanya mengandung racun. Mengkudu jenis Morinda Citrifolia L merupakan jenis mengkudu yang tidak mengandung racun dan termasuk dalam kategori tumbuhan tropis [1].

Penelitian [2] untuk klasifikasi buah kelapa dengan metode backpropagation memberikan tingkat akurasi sebesar $100 \%$. Penelitian ini bisa menghasilkan serta menigkatkan hasil akurasi untuk itu backpropagation merupakan proses dimana percobaan yang diulangi kembali untuk menentukan tujuan target agar bisa menghasilkan serta megurangi kesalahan atau error. Pada penelitian [3] yang serupa, mengidentifikasi varietas padi menggunakan citra digital dengan tingkat akurasi sekitar $76 \%-85 \%$. Hasil yang didapatkan mempunyai tujuan untuk mendeskripsikan geometri dan sebagai penentuan paramater.

Penelitian ini menggunakan metode jaringan syaraf tiruan backpropagation. Algoritma backpropagation merupakan metode pembelajaran dalam pewarisan yang sering digunakan pada perceptron dengan berbagai lapisan layar dalam pengubahan bobot dilapisan tersembunyi [4]. Penggunaan metode tersebut digunakan atas dasar pemecahan masalah yang mengandalkan bentuk buah mengkudu, sehingga dibutuhkan teknik sebagai pengoptimalan penilaian dalam proses pengambilan keputusan.

Tujuan dari penelitian ini untuk mengidentifikasi jenis tanaman mengkudu dari bentuk dan warna buah dengan menggunakan jaringan syaraf tiruan 
backpropagation cara untuk menghasilkan data yang akurat.

\section{TINJAUAN PUSTAKA}

Penelitian [2] pada tahun 2016 yang berjudul "Sistem Cerdas Untuk Klasifikasi Buah Kelapa Menggunakan Meode Backpropagation" dapat disimpulkan bahwa tujuan dari penelitian yaitu mengklasifikasi buah kelapa untuk sistem pengenalan buah dengan menggunakan metode backpropagation. Hasil proses dari penelitian didapatkan semua pola dapat dikenali dengan tingkat akurasisebesar $100 \%$.

Penelitian [5]pada tahun 2016 yang berjudul "Pengenalan Citra Buah Manggis Menggunakan Metode Jaringan Syaraf Tiruan Backpropagation" dapat disimpulkan bahwa tujuan dari penelitian yaitu mengklasifikasi buah manggis agar dapat dibedakan menjadi 2 jenis yaitu kualitas baik dan buruk. Metode yang diterapkan adalah backpropagation agar mudah dalam pemrosesan. Hasil dari penelitian ini dapat mengkelompokkan hasil dari segi kualitas.

Penelitian [6] pada tahun 2015 yang berjudul "Identifikasi Kematangan Buah Pisang Dengan Teknik Jaringan Syaraf Tiruan" dapat disimpulkan bahwa tujuan dari penelitian yaitu mengidentifikasi kematangan buah pisang agar bisa ditentukan mana buah pisang yang mentah, matang dan kelewat matang. Penelitian ini menerapkan metode backpropagation. Hasil dari penelitian ini tingkat keberhasilan identifikasi pada buah pisang menghasilkan akurasi yang akurat.

Penelitian [7] pada tahun 2016 yang berjudul "Implementasi Metode Backpropagation Untuk Mengidentifkasi Jenis Biji Kakao Yang Cacat Berdasarkan Bentuk Biji" dapat disimpulkan bahwa tujuan dari penelitian yaitu pembuatan program untuk menentukan kualitas pada biji kakao dengan menerapkan metode backpropagation untuk memperkecil kesalahan. Hasil dari penelitian ini mendapatkan tingkat akurasi sebesar $76 \%$ dalam penentuan kualitas biji kakao.

\section{METODE PENELITIAN}

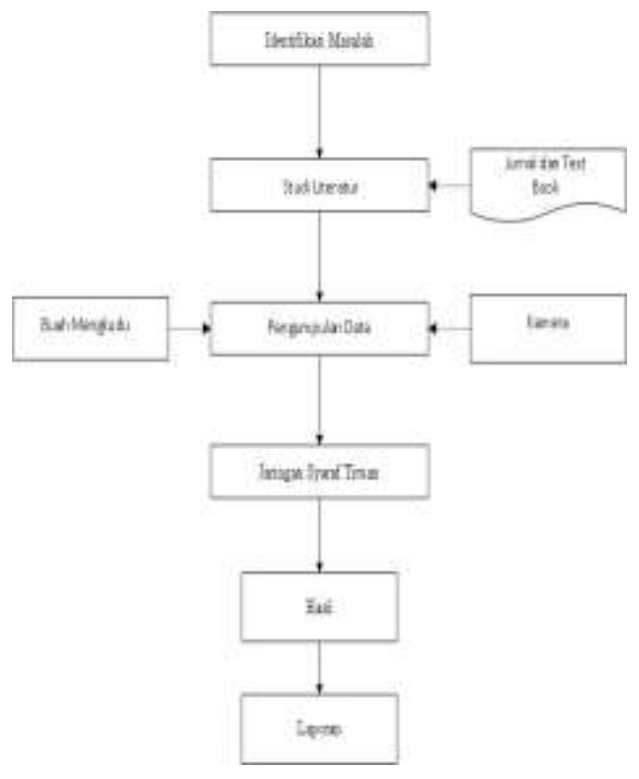

Gambar 1. Alur Penelitian

\section{A. Identifikasi Masalah}

Identifikasi pada suatu tanaman bisa dilihat dari data yang digunakan berupa dari segi buah, daun, batang, dan lainnya. Penelitian ini memfokuskan menggunakan buah tanaman mengkudu yang akan dijadikan objek dari proses identifikasi. Hal tersebut menjadi faktor yang signifikan untuk dilakukan pengamatan berfokus pada citra. Untuk itu maka diperlukan data terkait ciri fisik dari tanaman buah mengkudu yang diperlukan untuk proses pembelajaran JST.

\section{B. Studi Literatur}

Tahapan studi literatur ini adalah tahapan dimana mencari data tanaman mengkudu yang dimaksud untuk mengetahui informasi mengenai ciri buah mengkudu. Studi literatur dilakukan dengan mengambil data melalui textbook atau jurnal penelitian sebelumnya.

\section{Pengumpulan Data}

Pada tahap pengumpulan data ini sampel data citra buah mengukudu diambil melalui foto kamera dan gambar buah mengkudu yang ada di internet. Data yang dikumpulkan akan digunakan pada proses pelatihan dan pengujian. 


\section{Pelatihan dan Pengujian JST}

Setelah proses pengumpulan data pada tahapan sebelumnya. Data yang telah dikumpulkan tersebut selanjutnya digunakan untuk proses pelatihan dan pengujian jaringan syaraf tiruan yang akan dibuat. Data dibagi menjai dua kelompok yaitu data latih dan data uji.

\section{E. Hasil}

Setelah dilakukan pelatihan dan pengujian jaringan syaraf tiruan maka selanjutnya akan mendapatkan hasil pengujian dan pelatihan program. Hasil dari pengujian program akan berupa data statistik tingkat akurasi dari hasil pengujian dalam persen dan banyaknya epoch yang dilakukan. Jika data hasil pengujian dan pelatihan masih belum mencapai target yang diinginkan maka akan dilakukan pelatihan dan pengujian data ulang hingga mencapai target yang relevan.

\section{F. Laporan}

Jika hasil data pelatihan dan pengujian telah mencapai target data yang relevan maka selanjutnya akan dilakukan pembuatan laporan mengenai hasil pelatihan dan pengujian. Laporan akan dibentuk dalam sebuah jurnal atau data statistik.

Alur penelitian diawali dari untuk cara penerapan jaringan syaraf tiruan untuk identifikasi jenis buah mengkudu yang dimulai dari identifikasi masalah. Tahap berikutnya merupakan tahap studi literatur yang akan dikerjakan dan dapat diketahui konsep dan tahap yang dikerjakan. Tahap pengumpulan data yaitu dengan mengumpulkan informasi data citra mengkudu yang terdiri dari Morinda Officinalis, Morinda Fructus, Morinda Bracteata (Maluku), Morinda Tinctoria (Padang), Morinda Elliptica Ridl (Hutan), Morinda Umbellata (Akar), dan Morinda Citrifolia (Bogor). Kemudian melakukan pembagian data dari data citra untuk dijadikan data citra latih dan citra uji. Data citra uji nanti digunakan untuk pengujian hasil pelatihan JST.
Proses jaringan syaraf tiruan akan dilakukan tahapan yang dimulai dari grayscale, ekstrak ciri Gray Level Cooccourence Matrix (GLCM), pelatihan dan pengujian data citra yang menggunakan algoritma Backpropagation. Konversi citra akan menggunakan aplikasi MATLAB untuk mempermudah olah data citra kedepan.

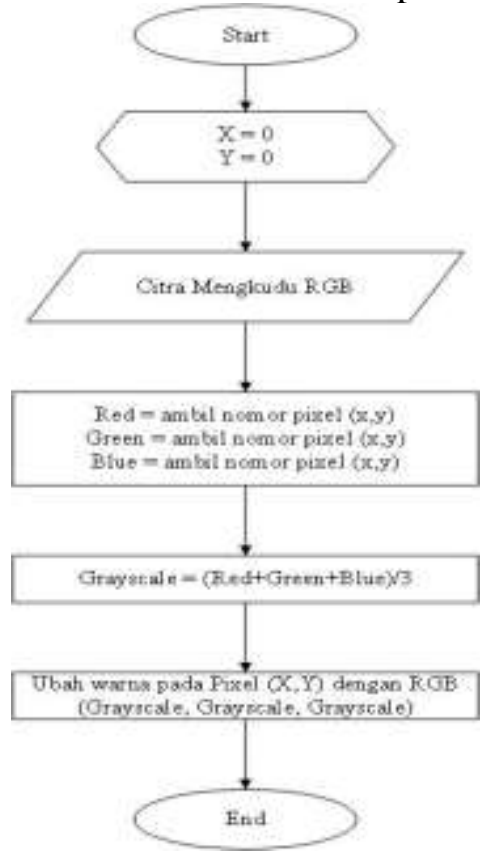

Gambar 2. Flowchart Grayscale

Tahap grayscale diawali dengan mengambil nilai pixel pada RGB untuk diekstrak ciri.kemudian setelah menjadi citra grayscale, dilakukan ekstrak ciri Gray Level Co-occourence Matrix (GLCM) dan setelah itu akan dilanjutkan pada tahap proses pelatihan dan pengujian JST.

\section{HASIL DAN PEMBAHASAN}

1. Pengumpulan Data

Data yang digunakan sebagai data uji dan data uji berupa gambar tekstur berbagai buah jenis mengkudu. Terdapat 7 gambar yang terdiri dari Morinda Officinalis, Morinda Fructus, Morinda Bracteata (Maluku), Morinda Tinctoria (Padang), Morinda Elliptica Ridl (Hutan), Morinda Umbellata (Akar), dan Morinda Citrifolia (Bogor). 5 gambar digunakan sebagai data latih dan 1 sebagai data uji. Gambar 3 sebagai berikut merupakan bentuk jenis buah mengkudu. 


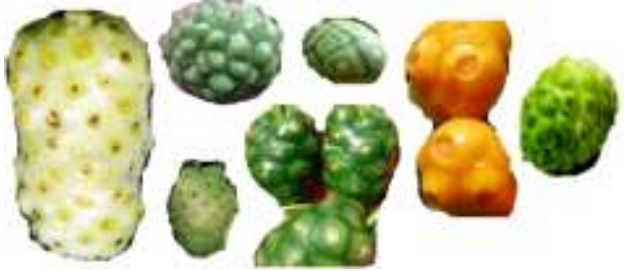

Gambar 3. Bentuk tekstur buah mengkudu

\section{Processing}

Data selanjutnya masuk ke tahap preprocessing. Data yang ada akan masuk ke proses resizing untuk menyamakan ukuran gambar menjadi 250 x 250 pixel. Setelah itu gambar masuk pada proses segmentasi citra yang dirubah menggunakan citra RGB.
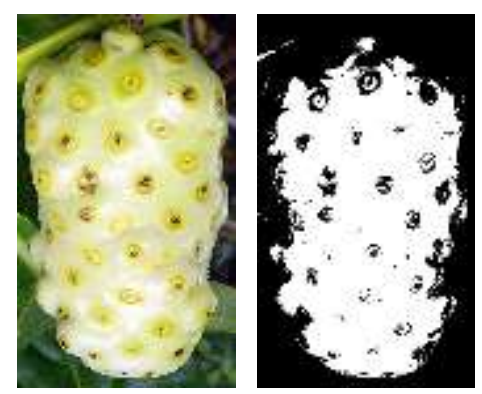

Gambar 4. Proses segmentasi citra

\section{Pelatihan dan Pengujian}

Proses tahap pelatihan dan pengujian didapatkan dari citra RGB yang diubah ke citra grayscale dan diekstrak ciri Gray Level Co-occourence Matrix (GLCM) agar didapatkan nilai homogenitas, energi, entropy, dan kontras untuk data input diproses pelatihan JST, nilai akurasi presentasi atau juga disebut tingkat akurasi identifikasi diperoleh dari pelatihan dan pengujian JST.

Pengujian JST menggunakan jarak $8 \mathrm{~cm}$ untuk mendapatkan nilai MSE kemudian akan dilanjutkan pada tahap pengujian. Pengujian menggunakan 2 hidden layer dengan masing - masing batasan MSE 1e-5, 1e-8, dan 1e-10. Pengujian diterapkan pada buah mengkudu berbagai jenis yang terdiri dari Morinda Officinalis, Morinda Fructus, Morinda Bracteata (Maluku), Morinda Tinctoria (Padang), Morinda Elliptica Ridl (Hutan), Morinda Umbellata (Akar), dan Morinda Citrifolia (Bogor) dengan menggunakan MATLAB sebagai media pengujian untuk mendapatkan nilai akurasi pada buah mengkudu dari berbagai jenis.

TABEL I.

HASIL UJI JST 8 CM MSE 1E-5

\begin{tabular}{|c|c|c|c|c|c|c|c|c|c|}
\hline \multicolumn{2}{|c|}{$\begin{array}{c}\text { Neuron } \\
\text { Lapisan } \\
\text { Tersembunyi }\end{array}$} & Hasil & $\begin{array}{l}\text { Morinda } \\
\text { Officinalis }\end{array}$ & $\begin{array}{l}\text { Morinda } \\
\text { Fructus }\end{array}$ & $\begin{array}{c}\text { Morinda } \\
\text { Bracteata } \\
\text { (Maluku) }\end{array}$ & $\begin{array}{l}\text { Morinda } \\
\text { Tinctoria } \\
\text { (Padang) }\end{array}$ & $\begin{array}{c}\text { Morinda } \\
\text { Elliptica } \\
\text { Ridl } \\
\text { (Hutan) } \\
\end{array}$ & $\begin{array}{c}\text { Morinda } \\
\text { Umbellata } \\
\text { (Akar) }\end{array}$ & $\begin{array}{c}\text { Morinda } \\
\text { Citrifolia } \\
\text { (Bogor) }\end{array}$ \\
\hline \multirow{3}{*}{15} & \multirow{3}{*}{15} & $\begin{array}{c}\text { Identifikasi } \\
\text { Benar }\end{array}$ & 4 & 2 & 2 & 3 & 4 & 4 & 3 \\
\hline & & Akurasi & $80 \%$ & $40 \%$ & $40 \%$ & $60 \%$ & $80 \%$ & $80 \%$ & $60 \%$ \\
\hline & & Rataan Akurasi & & & & $78 \%$ & & & \\
\hline \multirow{3}{*}{20} & \multirow{3}{*}{20} & $\begin{array}{c}\text { Identifikasi } \\
\text { Benar }\end{array}$ & 2 & 3 & 1 & 4 & 2 & 1 & 1 \\
\hline & & Akurasi & $40 \%$ & $60 \%$ & $20 \%$ & $80 \%$ & $40 \%$ & $20 \%$ & $20 \%$ \\
\hline & & Rataan Akurasi & & & & $64 \%$ & & & \\
\hline \multirow{3}{*}{25} & \multirow{3}{*}{25} & $\begin{array}{c}\text { Identifikasi } \\
\text { Benar }\end{array}$ & 2 & 1 & 3 & 1 & 2 & 3 & 2 \\
\hline & & Akurasi & $40 \%$ & $20 \%$ & $60 \%$ & $20 \%$ & $40 \%$ & $60 \%$ & $40 \%$ \\
\hline & & $\begin{array}{l}\text { Rataan } \\
\text { Akurasi }\end{array}$ & & & & $62 \%$ & & & \\
\hline \multirow{3}{*}{30} & \multirow{3}{*}{30} & $\begin{array}{c}\text { Identifikasi } \\
\text { Benar }\end{array}$ & 1 & 2 & 2 & 3 & 3 & 3 & 2 \\
\hline & & Akurasi & $20 \%$ & $40 \%$ & $40 \%$ & $60 \%$ & $60 \%$ & $60 \%$ & $40 \%$ \\
\hline & & $\begin{array}{l}\text { Rataan } \\
\text { Akurasi }\end{array}$ & & & & $58 \%$ & & & \\
\hline
\end{tabular}


TABEL II

HASIL UJI JST 8 CM MSE 1E-8

\begin{tabular}{|c|c|c|c|c|c|c|c|c|}
\hline $\begin{array}{c}\text { Neuron Lapisan } \\
\text { Tersembunyi }\end{array}$ & Hasil & $\begin{array}{l}\text { Morinda } \\
\text { Officinalis }\end{array}$ & $\begin{array}{l}\text { Morinda } \\
\text { Fructus }\end{array}$ & $\begin{array}{c}\text { Morinda } \\
\text { Bracteata } \\
\text { (Maluku) }\end{array}$ & $\begin{array}{l}\text { Morinda } \\
\text { Tinctoria } \\
\text { (Padang) }\end{array}$ & $\begin{array}{c}\text { Morinda } \\
\text { Elliptica } \\
\text { Ridl } \\
\text { (Hutan) }\end{array}$ & $\begin{array}{c}\text { Morinda } \\
\text { Umbellata } \\
\text { (Akar) }\end{array}$ & $\begin{array}{c}\text { Morinda } \\
\text { Citrifolia } \\
\text { (Bogor) }\end{array}$ \\
\hline \multirow{3}{*}{15} & $\begin{array}{c}\text { Identifikasi } \\
\text { Benar }\end{array}$ & 4 & 3 & 3 & 1 & 1 & 2 & 1 \\
\hline & Akurasi & $80 \%$ & $60 \%$ & $60 \%$ & $20 \%$ & $20 \%$ & $40 \%$ & $20 \%$ \\
\hline & $\begin{array}{l}\text { Rataan } \\
\text { Akurasi }\end{array}$ & & & & $58 \%$ & & & \\
\hline \multirow{3}{*}{20} & $\begin{array}{c}\text { Identifikasi } \\
\text { Benar }\end{array}$ & 2 & 4 & 1 & 3 & 1 & 1 & 2 \\
\hline & Akurasi & $40 \%$ & $80 \%$ & $20 \%$ & $60 \%$ & $20 \%$ & $20 \%$ & $40 \%$ \\
\hline & $\begin{array}{l}\text { Rataan } \\
\text { Akurasi }\end{array}$ & & & & $52 \%$ & & & \\
\hline \multirow{3}{*}{25} & $\begin{array}{c}\text { Identifikasi } \\
\text { Benar }\end{array}$ & 2 & 1 & 1 & 1 & 2 & 2 & 2 \\
\hline & Akurasi & $40 \%$ & $20 \%$ & $20 \%$ & $20 \%$ & $40 \%$ & $40 \%$ & $40 \%$ \\
\hline & $\begin{array}{l}\text { Rataan } \\
\text { Akurasi }\end{array}$ & & & & $48 \%$ & & & \\
\hline \multirow{3}{*}{30} & $\begin{array}{c}\text { Identifikasi } \\
\text { Benar }\end{array}$ & 3 & 1 & 1 & 2 & 1 & 4 & 2 \\
\hline & Akurasi & $60 \%$ & $20 \%$ & $20 \%$ & $40 \%$ & $20 \%$ & $80 \%$ & $40 \%$ \\
\hline & $\begin{array}{l}\text { Rataan } \\
\text { Akurasi }\end{array}$ & & & & $48 \%$ & & & \\
\hline
\end{tabular}

TABEL III

HASIL UJI JST 8 CM MSE 1E-10

\begin{tabular}{|c|c|c|c|c|c|c|c|c|c|}
\hline \multicolumn{2}{|c|}{$\begin{array}{l} \\
\text { Neuron Lapisan } \\
\text { Tersembunyi }\end{array}$} & Hasil & $\begin{array}{l}\text { Morinda } \\
\text { Officinalis }\end{array}$ & $\begin{array}{l}\text { Morinda } \\
\text { Fructus }\end{array}$ & $\begin{array}{c}\text { Morinda } \\
\text { Bracteata } \\
\text { (Maluku) }\end{array}$ & $\begin{array}{l}\text { Morinda } \\
\text { Tinctoria } \\
\text { (Padang) }\end{array}$ & $\begin{array}{c}\text { Morinda } \\
\text { Elliptica } \\
\text { Ridl } \\
\text { (Hutan) }\end{array}$ & $\begin{array}{c}\text { Morinda } \\
\text { Umbellata } \\
\text { (Akar) }\end{array}$ & $\begin{array}{c}\text { Morinda } \\
\text { Citrifolia } \\
\text { (Bogor) }\end{array}$ \\
\hline \multirow{3}{*}{15} & \multirow{3}{*}{15} & $\begin{array}{c}\text { Identifikasi } \\
\text { Benar }\end{array}$ & 3 & 4 & 1 & 4 & 1 & 2 & 4 \\
\hline & & Akurasi & $60 \%$ & $80 \%$ & $20 \%$ & $80 \%$ & $20 \%$ & $40 \%$ & $80 \%$ \\
\hline & & $\begin{array}{l}\text { Rataan } \\
\text { Akurasi }\end{array}$ & & & & $76 \%$ & & & \\
\hline \multirow{3}{*}{20} & \multirow{3}{*}{20} & $\begin{array}{c}\text { Identifikasi } \\
\text { Benar }\end{array}$ & 1 & 2 & 2 & 3 & 2 & 1 & 4 \\
\hline & & Akurasi & $20 \%$ & $40 \%$ & $40 \%$ & $60 \%$ & $40 \%$ & $20 \%$ & $80 \%$ \\
\hline & & $\begin{array}{l}\text { Rataan } \\
\text { Akurasi }\end{array}$ & & & & $62 \%$ & & & \\
\hline \multirow{3}{*}{25} & \multirow{3}{*}{25} & $\begin{array}{c}\text { Identifikasi } \\
\text { Benar }\end{array}$ & 2 & 1 & 2 & 3 & 1 & 2 & 3 \\
\hline & & Akurasi & $40 \%$ & $20 \%$ & $40 \%$ & $60 \%$ & $20 \%$ & $40 \%$ & $60 \%$ \\
\hline & & $\begin{array}{l}\text { Rataan } \\
\text { Akurasi }\end{array}$ & & & & $58 \%$ & & & \\
\hline \multirow{3}{*}{\multicolumn{2}{|c|}{30}} & $\begin{array}{c}\text { Identifikasi } \\
\text { Benar }\end{array}$ & 1 & 1 & 3 & 2 & 2 & 1 & 3 \\
\hline & & Akurasi & $20 \%$ & $20 \%$ & $60 \%$ & $40 \%$ & $20 \%$ & $20 \%$ & $60 \%$ \\
\hline & & $\begin{array}{l}\text { Rataan } \\
\text { Akurasi }\end{array}$ & & & & $52 \%$ & & & \\
\hline
\end{tabular}


TABEL IV

HASIL UJI JST 10 CM MSE 1E-5

\begin{tabular}{|c|c|c|c|c|c|c|c|c|c|}
\hline \multicolumn{2}{|c|}{$\begin{array}{c}\text { Neuron Lapisan } \\
\text { Tersembunyi }\end{array}$} & Hasil & $\begin{array}{l}\text { Morinda } \\
\text { Officinalis }\end{array}$ & $\begin{array}{c}\text { Morinda } \\
\text { Fructus }\end{array}$ & $\begin{array}{l}\text { Morinda } \\
\text { Bracteata } \\
\text { (Maluku) }\end{array}$ & $\begin{array}{l}\text { Morinda } \\
\text { Tinctoria } \\
\text { (Padang) }\end{array}$ & $\begin{array}{c}\text { Morinda } \\
\text { Elliptica } \\
\text { Ridl } \\
\text { (Hutan) } \\
\end{array}$ & $\begin{array}{c}\text { Morinda } \\
\text { Umbellata } \\
\text { (Akar) }\end{array}$ & $\begin{array}{c}\text { Morinda } \\
\text { Citrifolia } \\
\text { (Bogor) }\end{array}$ \\
\hline \multirow{3}{*}{15} & \multirow{3}{*}{15} & $\begin{array}{c}\text { Identifikasi } \\
\text { Benar }\end{array}$ & 3 & 2 & 1 & 3 & 3 & 2 & 4 \\
\hline & & Akurasi & $60 \%$ & $40 \%$ & $20 \%$ & $60 \%$ & $60 \%$ & $40 \%$ & $80 \%$ \\
\hline & & $\begin{array}{l}\text { Rataan } \\
\text { Akurasi }\end{array}$ & & & & $78 \%$ & & & \\
\hline \multirow{3}{*}{20} & \multirow{3}{*}{20} & $\begin{array}{c}\text { Identifikasi } \\
\text { Benar }\end{array}$ & 4 & 3 & 3 & 4 & 4 & 3 & 3 \\
\hline & & Akurasi & $80 \%$ & $60 \%$ & $60 \%$ & $80 \%$ & $80 \%$ & $60 \%$ & $60 \%$ \\
\hline & & $\begin{array}{l}\text { Rataan } \\
\text { Akurasi }\end{array}$ & & & & $80 \%$ & & & \\
\hline \multirow{3}{*}{25} & \multirow{3}{*}{25} & $\begin{array}{c}\text { Identifikasi } \\
\text { Benar }\end{array}$ & 2 & 3 & 4 & 2 & 2 & 4 & 4 \\
\hline & & Akurasi & $40 \%$ & $60 \%$ & $80 \%$ & $40 \%$ & $40 \%$ & $80 \%$ & $80 \%$ \\
\hline & & $\begin{array}{l}\text { Rataan } \\
\text { Akurasi }\end{array}$ & & & & $76 \%$ & & & \\
\hline \multirow{3}{*}{30} & \multirow{3}{*}{30} & $\begin{array}{c}\text { Identifikasi } \\
\text { Benar }\end{array}$ & 3 & 4 & 3 & 3 & 3 & 3 & 3 \\
\hline & & Akurasi & $60 \%$ & $80 \%$ & $60 \%$ & $60 \%$ & $60 \%$ & $60 \%$ & $60 \%$ \\
\hline & & $\begin{array}{l}\text { Rataan } \\
\text { Akurasi }\end{array}$ & & & & $64 \%$ & & & \\
\hline
\end{tabular}

TABEL V

HASIL UJI JST 10 CM MSE 1E-8

\begin{tabular}{|c|c|c|c|c|c|c|c|c|}
\hline $\begin{array}{c}\text { Neuron Lapisan } \\
\text { Tersembunyi }\end{array}$ & Hasil & $\begin{array}{l}\text { Morinda } \\
\text { Officinalis }\end{array}$ & $\begin{array}{l}\text { Morinda } \\
\text { Fructus }\end{array}$ & $\begin{array}{l}\text { Morinda } \\
\text { Bracteata } \\
\text { (Maluku) }\end{array}$ & $\begin{array}{l}\text { Morinda } \\
\text { Tinctoria } \\
\text { (Padang) }\end{array}$ & $\begin{array}{c}\text { Morinda } \\
\text { Elliptica } \\
\text { Ridl } \\
\text { (Hutan) }\end{array}$ & $\begin{array}{c}\text { Morinda } \\
\text { Umbellata } \\
\text { (Akar) }\end{array}$ & $\begin{array}{c}\text { Morinda } \\
\text { Citrifolia } \\
\text { (Bogor) }\end{array}$ \\
\hline \multirow{3}{*}{15} & $\begin{array}{c}\text { Identifikasi } \\
\text { Benar }\end{array}$ & 4 & 4 & 3 & 3 & 3 & 4 & 3 \\
\hline & Akurasi & $80 \%$ & $80 \%$ & $60 \%$ & $60 \%$ & $60 \%$ & $80 \%$ & $60 \%$ \\
\hline & $\begin{array}{l}\text { Rataan } \\
\text { Akurasi }\end{array}$ & & & & $76 \%$ & & & \\
\hline \multirow{3}{*}{20} & $\begin{array}{c}\text { Identifikasi } \\
\text { Benar }\end{array}$ & 3 & 2 & 4 & 4 & 4 & 2 & 4 \\
\hline & Akurasi & $60 \%$ & $40 \%$ & $80 \%$ & $80 \%$ & $80 \%$ & $40 \%$ & $80 \%$ \\
\hline & $\begin{array}{c}\text { Rataan } \\
\text { Akurasi }\end{array}$ & & & & $72 \%$ & & & \\
\hline \multirow{3}{*}{25} & $\begin{array}{c}\text { Identifikasi } \\
\text { Benar }\end{array}$ & 3 & 3 & 3 & 2 & 3 & 4 & 3 \\
\hline & Akurasi & $60 \%$ & $60 \%$ & $60 \%$ & $40 \%$ & $60 \%$ & $80 \%$ & $60 \%$ \\
\hline & $\begin{array}{l}\text { Rataan } \\
\text { Akurasi }\end{array}$ & & & & $68 \%$ & & & \\
\hline \multirow{3}{*}{30} & $\begin{array}{c}\text { Identifikasi } \\
\text { Benar }\end{array}$ & 4 & 3 & 4 & 4 & 3 & 3 & 3 \\
\hline & Akurasi & $60 \%$ & $60 \%$ & $80 \%$ & $80 \%$ & $60 \%$ & $60 \%$ & $60 \%$ \\
\hline & $\begin{array}{l}\text { Rataan } \\
\text { Akurasi }\end{array}$ & & & & $74 \%$ & & & \\
\hline
\end{tabular}


TABEL VI

HASIL UJI JST 10 CM MSE 1E-10

\begin{tabular}{|c|c|c|c|c|c|c|c|c|c|}
\hline \multicolumn{2}{|c|}{\begin{tabular}{|c|} 
Neuron \\
Lapisan \\
Tersembuny \\
i \\
\end{tabular}} & Hasil & $\begin{array}{c}\text { Morinda } \\
\text { Officinalis }\end{array}$ & $\begin{array}{c}\text { Morinda } \\
\text { Fructus }\end{array}$ & $\begin{array}{c}\text { Morinda } \\
\text { Bracteata } \\
\text { (Maluku) }\end{array}$ & $\begin{array}{l}\text { Morinda } \\
\text { Tinctoria } \\
\text { (Padang) }\end{array}$ & $\begin{array}{c}\text { Morinda } \\
\text { Elliptica } \\
\text { Ridl } \\
\text { (Hutan) }\end{array}$ & $\begin{array}{c}\text { Morinda } \\
\text { Umbellata } \\
\text { (Akar) }\end{array}$ & $\begin{array}{c}\text { Morinda } \\
\text { Citrifolia } \\
\text { (Bogor) }\end{array}$ \\
\hline \multirow{3}{*}{15} & \multirow{3}{*}{15} & $\begin{array}{c}\text { Identifikasi } \\
\text { Benar }\end{array}$ & 3 & 4 & 4 & 4 & 3 & 4 & 4 \\
\hline & & Akurasi & $60 \%$ & $80 \%$ & $80 \%$ & $80 \%$ & $60 \%$ & $80 \%$ & $80 \%$ \\
\hline & & $\begin{array}{l}\text { Rataan } \\
\text { Akurasi }\end{array}$ & & & & $86 \%$ & & & \\
\hline \multirow{3}{*}{20} & \multirow{3}{*}{20} & $\begin{array}{c}\text { Identifikasi } \\
\text { Benar }\end{array}$ & 2 & 4 & 3 & 4 & 4 & 3 & 4 \\
\hline & & Akurasi & $40 \%$ & $80 \%$ & $60 \%$ & $80 \%$ & $80 \%$ & $60 \%$ & $80 \%$ \\
\hline & & $\begin{array}{l}\text { Rataan } \\
\text { Akurasi }\end{array}$ & & & & $84 \%$ & & & \\
\hline \multirow{3}{*}{25} & \multirow{3}{*}{25} & $\begin{array}{c}\text { Identifikasi } \\
\text { Benar }\end{array}$ & 4 & 4 & 4 & 3 & 3 & 4 & 3 \\
\hline & & Akurasi & $80 \%$ & $80 \%$ & $80 \%$ & $60 \%$ & $60 \%$ & $80 \%$ & $60 \%$ \\
\hline & & $\begin{array}{l}\text { Rataan } \\
\text { Akurasi }\end{array}$ & & & & $80 \%$ & & & \\
\hline \multirow{3}{*}{30} & \multirow{3}{*}{30} & $\begin{array}{c}\text { Identifikasi } \\
\text { Benar }\end{array}$ & 3 & 4 & 3 & 3 & 4 & 3 & 4 \\
\hline & & Akurasi & $60 \%$ & $80 \%$ & $60 \%$ & $60 \%$ & $80 \%$ & $60 \%$ & $80 \%$ \\
\hline & & $\begin{array}{l}\text { Rataan } \\
\text { Akurasi }\end{array}$ & & & & $76 \%$ & & & \\
\hline
\end{tabular}

Tabel I dan III mencantumkan bahwa pada batasan MSE 1e-5 dan MSE 1e-10 menghasilkan nilai akurasi tinggi pada batasannya.Hasil penelitian dari pengujian yang sudah dijelaskan pada setiap tabel JST 8 $\mathrm{cm}$ dan $10 \mathrm{~cm}$ yang terdiri dari hasil uji MSE 1e-5, 1e-8, dan 1e-10 bahwa nilai optimal ratarata akurasi yang muncul dari semua tabel adalah $86 \%$.

\section{KESIMPULAN}

Metode algoritma jaringan syaraf tiruan Backpropagation menggunakan citra gryscale dapat diimplementasikan dengan baik dalam hal mengidentifikasi jenis buah mengkudu dengan nilai akurasi rata-rata sebesar $86 \%$. Data hasil pengujian tertinggi didapatkan pada hasil uji JST jarak $10 \mathrm{~cm}$ MSE 1e-10 dan terendah didapatkan pada hasil uji JST jarak 8 cm MSE 1e-8.

Penelitian ini diharapkan dapat memberikan sebuah informasi dari hasil identifikasi jenis buah mengkudu dengan menggunakan algoritma jaringan syaraf tiruan Backpropagation memiliki hasil akurasi yang baik dengan menyentuh nilai angka akurasi sebesar $86 \%$.

\section{REFERENSI}

[1] I. S. Amilah, "ISSN 1412 - 1840

AKTIVITAS LARVASIDA

EKSTRAK DAUN BANDOTAN (

Ageratum conyzoides L .) DAN

BUNGA KENANGA ( Cananga odorata L . ) TERHADAP NYAMUK

DEMAM BERDARAH ( Aedes

Aegypti L .)," vol. 7, no. 2, pp. 24-27, 2014.

[2] Abdullah and Usman, "Sistem cerdas untuk klasifikasi buah kelapa menggunakan metode backpropagation,” pp. 87-95, 2016.

[3] M. L. Widiastuti, "Identifikasi Varietas Padi Menggunakan Pengolahan Citra Digital dan Analisis Diskriminan Identification of Rice Variety using Image Processing and," pp. 89-96, 2015.

[4] I. Sriwahyuni Purba and A. Wanto, "Prediksi Jumlah Nilai Impor Sumatera Utara Menurut Negara Asal Menggunakan Algoritma 
Backpropagation," Techno.COM, vol. 17, no. 3, pp. 302-311, 2018.

[5] D. Nursantika et al., "METODE JARINGAN SYARAF TIRUAN BACKPROPAGATION," no. Selisik, 2016.

[6] T. M. Siregar, L. A. Harahap, and A. Rohanah, "TEKNIK JARINGAN SYARAF TIRUAN ( Identification of
Banana Maturity ( Musa paradisiaca ) with Artificial Neural Network )," vol. 3, no. 2, pp. 261-265, 2015.

[7] S. Nurmuslimah, "Implementasi Metode Backpropagation untuk mengidentifikasi jenis biji Kakao yang cacat berdasarkan bentuk biji," vol. 2, no. 2, pp. 91-98, 2016. 